\title{
Epidemiology of Renal Failure in Children at the Pediatric University Hospital Charles De-Gaulle of Ouagadougou (Burkina Faso)
}

\author{
Coulibaly Gérard ${ }^{*}$, Savadogo Hamidou ${ }^{2}$, Bakoné B. Evariste², Karambiri Adama Roger ${ }^{1}$, \\ Kouéta Fla², Hien Kpienoba Manan', Champion Gérard³, Lengani Adama1, Yé Diarra² \\ ${ }^{1}$ Department of Nephrology and Hemodialysis, University Hospital Center Yalgado Ouedraogo, Ouagadougou, \\ Burkina Faso \\ ${ }^{2}$ Department of Medical Pediatrics, Pediatrics University Hospital Center Charles De-Gaulle, Ouagadougou, \\ Burkina Faso \\ ${ }^{3}$ Pediatrics Nephrology Service, Pediatrics Federation, CHU, Angers Cedex, France \\ Email: "coulibalygerard@hotmail.fr, interne.pediatrie@gmail.com, ebakone@gmail.com, \\ adamaroger@yahoo.fr, kouetafla@yahoo.com, hienmanan@yahoo.fr, gerchampion@wanadoo.fr, \\ alengani2002@yahoo.fr, yediarra@hotmail.com
}

Received 20 February 2016; accepted 17 March 2016; published 21 March 2016

Copyright (C) 2016 by authors and Scientific Research Publishing Inc.

This work is licensed under the Creative Commons Attribution International License (CC BY).

http://creativecommons.org/licenses/by/4.0/

(c) (i) Open Access

\section{Abstract}

Objective: Renal failure (RF) is a serious condition that is still insufficiently evaluated in our context. We wanted to know its epidemiology at the Pediatrics University Hospital Center Charles De-Gaulle (PUHC-CDG) of Ouagadougou. Patients and Methods: We retrospectively studied all children aged from three to fifteen years old who were diagnosed with renal failure (RF) in the Department of Medical Pediatrics, from January 1, 2011 to December 31, 2013. RF was defined by a glomerular filtration rate (GFR) less than $80 \mathrm{~mL} / \mathrm{min} / 1.73 \mathrm{~m}^{2}$, estimated by the formula of Pottel et al., which ignored the size that was rarely found in the medical records. The department constantly lacked pediatric blood pressure monitors or urinary strips. Results: In total, 119 cases of RF (3.3\% of all admissions) were collected. They were about acute RFs (ARFs), chronic RFs (CRFs), and Unclassified RFs (URFs), respectively in $28.6 \%, 2.5 \%$ and $68.9 \%$ of cases. The overall average age of patients was $6.7 \pm 3.4$ years old. The average GFR was $35.2 \pm 22.2 \mathrm{~mL} / \mathrm{min} / 1.73 \mathrm{~m}^{2}$. The mechanism of ARF was presumed to be organic in 26 cases $(76.5 \%)$. The most common presumed etiology was malaria $(47.9 \%)$. Twelve patients $(10.1 \%)$ died. Conclusion: RF was common at the PUHC-CDG but it was unclassified in over half of the cases. The diagnosis was based on the estimation of the GFR by Pottel et al.'s formula which was a good alternative to the Schwartz's formula. The improvement of human and material resources would certainly help for a screening and characterization of RF at the PUHC-CDG.

${ }^{*}$ Corresponding author.

How to cite this paper: Gérard, C., Hamidou, S., Evariste, B.B., Roger, K.A., Fla, K., Manan, H.K., Gérard, C., Adama, L. and Diarra, Y. (2016) Epidemiology of Renal Failure in Children at the Pediatric University Hospital Charles De-Gaulle of Ouagadougou (Burkina Faso). Open Journal of Pediatrics, 6, 141-148. http://dx.doi.org/10.4236/ojped.2016.61021 


\section{Keywords}

\section{Burkina Faso, Epidemiology, Glomerular Filtration Rate, Pediatrics, Renal Failure}

\section{Introduction}

The incidence of acute renal failure (ARF) in the general population is about 2000 to 3000 per million persons per year for mild and moderate ARF and 200 to 300 per million persons for ARF requiring renal replacement therapy [1]. Pediatric data on the epidemiology of ARF are rare; they vary depending on the country. Overall, the prevalence of ARF is growing all over the world [2]. The situation in tropical Africa seems to be more alarming. Indeed, some environmental factors (infectious, acute dehydration) and socio-cultural factors (traditional, over-the-counter products use) in this region of the world contribute to increasing the risk of ARF [3]. $\mathrm{CRF}$, which may be a complication, is a major public health issue because of its increasing prevalence, severity and the high cost related to the treatment. In Burkina Faso, renal failure (RF) data are particularly rare in children. The hospital incidence of ARF was 19.6 cases per year [Kiendrebeogo; personal data] in the Department of Pediatrics of University Hospital Center Yalgado Ouedraogo in Ouagadougou, and a prevalence of $1.79 \%$ over six months was noted in the Department of Pediatrics of CHU-SS [Nebie; personal data]. RF cases are frequently treated at the Pediatric University Hospital Center Charles De-Gaulle (PUHC-CDG) despite difficulties related to the lack medical equipment and the absence of specialist in pediatric nephrology, among others. It is in such context that we conducted this study in order to know the epidemiology of RF in the Department of Pediatrics of the PUHC-CDG.

\section{Patients and Methods}

We conducted a retrospective study, over a period of three years, of medical records of in-patients from January 1, 2011 to December 31, 2013. It took place in the department of Pediatrics at the PUHC-CDG in Ouagadougou, Burkina Faso. In this department, which has no nephrologist, pediatric blood pressure monitors and urine test strips are not consistently available. These activities were disturbed for moments by repair works from 2011 to 2013. The paraclinic workup was done in another UHC or in a private health structure whenever it was not possible at the PUHC-CDG.

We included in the study all children between three and fifteen years during the study period, who were diagnosed with RF at the admission or during hospitalization. During the period covered by the study, there wasn't a treatment protocol for renal failure. We retained the operational definitions below:

- Renal failure (RF): glomerular filtration rate (GFR) less than $80 \mathrm{~mL} / \mathrm{min} / 1.73 \mathrm{~m}^{2}$. GFR was estimated using the formula of Pottel et al. [4]:

$$
G F R=\frac{107.3}{(S c r / Q)}
$$

GFR: glomerular filtration rate expressed in $\mathrm{mL} / \mathrm{min} / 1.73 \mathrm{~m}^{2}$. SCR: serum creatinine expressed in $\mathrm{mg} / \mathrm{dL}$ $(\mu \mathrm{mol} / \mathrm{L}: 88.4) . Q=(00.0270 \times$ Age $)+0.2329$

$\checkmark$ The renal failure was acute (ARF) in the event of normalization of the GFR before three months. This ARF was considered functional [5] in the situations that can cause renal hypoperfusion: fluid and blood loss (acute hemorrhage, dehydration, the third sector), shock. The ARF was organic [6] in case of presumed glomerular, tubular, or interstitial vascular injury. Obstructive ARF was confirmed by highlighting bilateral dilation (or on single kidney) of pyelocaliceal cavities on renal ultrasound.

$\checkmark$ The Renal failure was considered chronic (CRF) in cases of already known CRF or persistence of RF beyond three months.

$\checkmark$ For other cases of RF, we did not have enough data to categorize them as ARF or CRF. Therefore, theywereconsideredunclassifiable (URF).

- Hypertension (HTN): we used the formulas developed by Somu et al. [7], which allow to estimate the 95th percentile (in $\mathrm{mm} \mathrm{Hg}$ ) simply on the basis of the age in years, regardless of the gender:

$\checkmark$ Systolic value (95th percentile): $1-17$ years $=100+($ age $\times 2)$ 
$\checkmark$ Diastolic value (95th percentile): $1-10$ years $=60+($ age $\times 2)$; $11-17$ years old $=70+$ age

We collected sociodemographic data, the mode and reasons of admission into the department, personal and family medical history, clinical and paraclinical data at admission time, treatment modalities, and outcome of patients. The mode of admission was a "reference" If the patient came from a lower level in the health pyramid of Burkina Faso, and "transfer" if the patient came from another department of the UPHC-CDG or another UHC.

Presumed etiologies were identified. The elements of their diagnosis were those commonly accepted. For example, the diagnosis of severe malaria was based on the WHO definition. We didn't have any results of dengue fever serology or assay of glucose-6-phosphate dehydrogenase activity.

The data was introduced and processed in a computer using Epi Info software 3.5.1. The comparison of qualitative variables was done by using the khi2 test and that of quantitative variables by using the analysis of variance test. The statistical significance of these tests was reached for $\mathrm{p}<0.05$.

\section{Results}

\subsection{Sociodemographic Data}

One hundred nineteen patients admitted into the department during the study period had renal failure, a hospital incidence rate of 3.3\%. The type of renal failure was ARF (34 cases or 28.6\%), CRF (3 cases or 2.5\%); and undetermined (82 cases or 68.9\%). We found 10 patients in 2011, 29 patients in 2012 and 80 patients in 2013. The annual incidence of RF was 39.7 cases. It was 11.3 and 1 respectively for ARF and CRF.

The patients were divided into 70 boys (58.8\%) and 49 girls (41.2\%). Their average age was $6.7 \pm 3.4$ years old. They were divided into age-classes of [3 - 5[, [5 - 10[ and [10 - 15 [years old, which were respectively 45 (37.8\%), 48 (40.3\%) and 26 (21.8\%). The residence places of patients were rural (33 cases or 28.7\%), semiurban (15 cases or $13 \%)$ and urban (67 cases or $58.3 \%)$.

\subsection{Mode and Reasons for Admission}

In $71.8 \%$ of the cases, patients were referred from peripheral health facilities. The other patients were admitted either directly (20.5\% of cases) or after being transferred from another department (7.7\% of cases). The main reasons for consultation were fever (39 cases or 32.8\%), vomiting (33 cases; $27.7 \%$ ), anemia (27 cases; 22.7\%), abdominal pain (25 cases; $21 \%$ ) and edema of the lower limbs with or without swelling of the face (15 cases; $12.6 \%)$.

\subsection{Clinical Signs}

The clinical signs at the admission were dominated by fever (49.5\%), jaundice (19.3\%), edema of the lower limbs (16\%), swelling of the face (15.1\%), hemoglobinuria (16.8\%), ascites (7.6\%), and pharyngitis (5.9\%). The blood pressure at the admission was measured for 33 patients (27.7\% of patients). The average blood pressure readings were $123.9 \pm 40.3 \mathrm{~mm} \mathrm{Hg}$ (extremes: 80 and 230) and $77.6 \pm 28.8 \mathrm{~mm} \mathrm{Hg}$ (extremes: 35 and 150) respectively for the systolic blood pressure (SBP) and diastolic blood pressure (DBP).

\subsection{Paraclinical Signs}

The urea was measured for 112 patients (94.1\%) at the admission. It was in average $16.6 \pm 17.1 \mathrm{mmol} / \mathrm{L}$ (extremes: 1.2 and 80.1).

The Serum creatinine was available for 114 patients at the admission time. It was in average $251.5 \pm 330.7$ $\mu \mathrm{mol} / \mathrm{L}$ (extremes: 40 and 1992). The estimated GFR of patients was $35.2 \pm 22.2 \mathrm{~mL} / \mathrm{min} / 1.73 \mathrm{~m}^{2}$ (extremes: 2 and 74.8).

During hospitalization, five patients or $4.2 \%$ of patients, showing normal renal function at the admission, had a decline in the estimated GFR. Their average serum creatinine that led to the diagnosis of RF was $224.7 \pm 242.6$ $\mu \mathrm{mol} / \mathrm{L}$ (extremes: 45 and 595) and the estimated GFR was $46.9 \pm 34.4 \mathrm{~mL} / \mathrm{min} / 1.73 \mathrm{~m}^{2}$ (extremes: 5.9 and 78.7).

The other biochemical and hematological parameters measured at the admission are summarized in Table 1 and Table 2. The cytobacteriological analysis of the urine was done for 19 patients. Five patients had a urinary 
Table 1. Mean serum creatinine and glomerular filtration rate (GFR) of patients at admission.

\begin{tabular}{ccccccc}
\hline & \multicolumn{2}{c}{ ARF } & \multicolumn{2}{c}{ CRF } & \multicolumn{2}{c}{ IRI } \\
\cline { 2 - 7 } & Creatinemia $^{*}$ & GFR & Creatinemia $^{*}$ & GFR & Créatinine $^{*}$ & DFG \\
\hline $\begin{array}{c}\text { Global } \\
\text { By gender }\end{array}$ & $482.2 \pm 403.2$ & $17.4 \pm 14.5$ & $486.3 \pm 120.4$ & $9.9 \pm 3.3$ & $149 \pm 242.6$ & $43.4 \pm 20.1$ \\
Boys & $516.8 \pm 458.7$ & $16.8 \pm 13.4$ & 625 & 6.4 & $123.4 \pm 114.9$ & $42.9 \pm 19.4$ \\
Girls & $437.6 \pm 329.7$ & $18.2 \pm 16.1$ & $162.0 \pm 12.7$ & $11.7 \pm 1.7$ & $185.1 \pm 350.2$ & $44.1 \pm 21.4$ \\
By age & & & & & & \\
{$[3$ - 5[ years } & $321.3 \pm 185.6$ & $13.4 \pm 8.8$ & - & & & \\
{$[5-10[$ years } & $525.9 \pm 419.5$ & $16.9 \pm 14.7$ & $516.5 \pm 153.4$ & $8.4 \pm 2.9$ & $199.2 \pm 376.9$ & $46.9 \pm 16.7$ \\
{$[10-15[$ years } & $530.1 \pm 505.0$ & $22.0 \pm 18.0$ & 426 & 12.9 & $209.0 \pm 170.9$ & $37.6 \pm 19.9$ \\
\hline
\end{tabular}

ARF: acute renal failure; CRF: chronic renal failure; URF: Unclassifiablerenalfailure. ${ }^{*}$ : serum creatinine (expressed as $\left.\mu \mathrm{mol} / \mathrm{L}\right)$.

Table 2. Mean of biochemical and hematological parameters values depending on the type of kidney failure.

\begin{tabular}{ccccccc}
\hline & \multicolumn{2}{c}{ ARF } & \multicolumn{2}{c}{ CRF } & \multicolumn{2}{c}{ IRI } \\
\cline { 2 - 6 } & $\mathbf{n ~ ( \% )}$ & $\mathbf{m} \pm$ SD & $\mathbf{n}(\%)$ & $\mathbf{m} \pm$ SD & n (\%) & m $\pm \mathbf{D S}$ \\
\hline Azotemia (mmol/L) & $31(91.2)$ & $30.5 \pm 22.2$ & $2(66.7)$ & $16.7 \pm 2.3$ & $79(96.3)$ & $11.0 \pm 10.9$ \\
Natremia (mmol/L) & $16(47.1)$ & $135.8 \pm 10.6$ & $1(33.3)$ & 147.0 & $22(26.8)$ & $137.4 \pm 5.7$ \\
Kaliemia (mmol/L) & $16(47.1)$ & $4.5 \pm 0.9$ & $1(33.3)$ & 5.2 & $22(26.8)$ & $4.2 \pm 0.8$ \\
Calcemia (mmol/L) & $16(47.1)$ & $2.0 \pm 0.3$ & $1(33.3)$ & 1.1 & $27(32.9)$ & $2.2 \pm 0.4$ \\
Serum bicarbonate (mmol/L) & $12(35.3)$ & $17.6 \pm 4.9$ & $0(0)$ & - & $22(26.8)$ & $18.1 \pm 6.2$ \\
Serummagnesium (mmol/L) & $8(23.5)$ & $1 \pm 0.1$ & $1(33.3)$ & 0.6 & $16(19.5)$ & $0.9 \pm 0.2$ \\
Serum phosphate (mmol/L) & $8(23.5)$ & $2.6 \pm 1.0$ & $0(0)$ & - & $14(17.1)$ & $1.6 \pm 0.7$ \\
Glycemia (mmol/L) & $31(91.2)$ & $4.7 \pm 1.7$ & $2(66.7)$ & $4.3 \pm 1.3$ & $71(86.6)$ & $5.3 \pm 3.8$ \\
CRP (mg/dL) & $1(2.9)$ & 24 & $0(0)$ & - & $4(4.9)$ & $22.2 \pm 28.4$ \\
Uricemia (mg/L) & $0(0)$ & - & $0(0)$ & - & $1(1.2)$ & 547 \\
PU (mg/kg/24hours) & $12(47.1)$ & $79.9 \pm 152.5$ & $3(100)$ & $130 \pm 59.0$ & $3(3.7)$ & $26.0 \pm 13.1$ \\
Hemoglobin (g/dL) & $33(97.1)$ & $6.9 \pm 2.72$ & $3(100)$ & $9.5 \pm 3.2$ & $80(97.6)$ & $8.8 \pm 3.5$ \\
Leukocytes(elements/mm $)^{*}$ & $32(94.1)$ & $12,687.5 \pm 6364.1$ & $3(100)$ & $13,800 \pm 5021$ & $75(91.5)$ & $12,522.7 \pm 9748.7$ \\
Platelets (elements/mm $)^{*}$ & $32(94.1)$ & $303,656.3 \pm 173,309.5$ & $3(100)$ & $300,333.3 \pm 7148.4$ & $74(90.2)$ & $283,783.8 \pm 136,772.6$ \\
\hline
\end{tabular}

CRP: C Reactiv Protein; ARF: Acute renal failure; CRF: Chronicrenal failure; URF: Unclassifiable renal failure; $\mathrm{n}$ : number; \%: percentage; $m \pm$ SD: mean \pm standard deviation; PU: proteinuria; ${ }^{*}$ : complet blood count parameters.

tract infection with urinary symptoms. The following germs have been isolated: Escherichia coli, Enterococcus sp, Staphylococcus aureus and Staphylococcus saprophyticus.

The abdominal and/or pelvic ultrasound was ordered for 44 patients or $37 \%$ of the patients. It has allowed us to find:

- A normal ultrasound for seven patients or $15.9 \%$ of the 44 patients;

- In the other cases we found the following anomalies:

$\checkmark$ kidneys: dedifferentiated kidneys (26 cases), hyperechogenicity (seven cases), irregular borders of the kidneys (one case);

$\checkmark$ ureters: bilateral stenosis (one case);

\subsection{Mechanism of Renal Failure and Presumed Etiologies}

The presumed mechanism of ARF was identified in 33 cases out of 34. It was:

- Organic ARF in 26 cases (76.5\% of cases of ARF): the context was a hemoglobinuria (23 cases recorded before or during hospitalization), and an acute post-streptococcal glomerulonephritis. The hemoglobinuria 
was linked to a severe malaria (17 cases) treated or not with quinine, a viral hepatonephritis B or C (5 cases) or probably drug-related (1 case);

- Functional ARF in six cases (7.6\%) related to a severe hypovolemia seen in nephrotic syndrome (3 cases) or a severe gastroenteritis (3 cases);

- One case (2.9\%) of obstructive ARF due to bilateral ureteral stenosis of unspecified cause in the medical record.

The presumed etiological damage in the three cases of CRF was chronic glomerulonephritis associated with nephrotic syndrome. In the 82 cases of URF, the mechanism of the renal damage could not be clarified.

The main presumed etiologies found in our patients were: severe malaria (52 cases), acute infectious gastroenteritis (8 cases), nephrotic syndrome (7 cases), acute post-streptococcal glomerulonephritis (6 cases), sepsis (5 cases), and viral hepatitis B or C (5 cases). The other presumed etiologies were represented each with three cases: envenomation by scorpion or snake bite, hypertension and typhoid fever.

\subsection{Evolution}

The average length of hospital stay was $10.2 \pm 10.1$ days (extremes: 1 and 61). The clinical-biological improvement was observed in 90 patients (75.6\%). Thirteen (10.9\%) were lost to follow-up. The remaining four patients were transferred in the department of nephrology and hemodialysis at the University Hospital Center Yalgado Ouedraogo of Ouagadougou.

Twelve patients (10.1\%) with an average age of $6.5 \pm 4.3$ years old (extremes: 3 and 13) died. The main causes of death were: severe malaria (five cases), septicemia (two cases), severe anemia (two cases). The time of occurrence of death was $8.7 \pm 16.8$ days old (extremes: 1 and 61 ).

\section{Discussion}

Because of the retrospective nature of the study, all medical files did not contain all of the information sought. In addition, data on patients' height were missing in the folders. Therefore, using the Schwartz formula to estimate the creatinine clearance was not possible. However, this formula remains the best-known and oldest in the evaluation of renal function in children [8]. So, we used the formula developed by Pottel et al. in 2012, because it is simple to use, and has a performance close to that of Schwartz and independent of the height measurement [4]. It is a good alternative to the Schwartz formula, particularly in our context where the measurement of the height is not always available [9].

The rate of URF in our series was very high. It showed the difficulties encountered by practitioners in the paraclinical exploration of patients in Burkina Faso. These problems are mostly related to ignorance and/or lack of financial resources of patients or their relatives, failure or malfunction of the equipment of healthcare centers. The incidence of ARF and CRF in our study should therefore be discussed taking into account the underestimate (much more for the ARF) induced by the high rate of URF.

The hospital incidence of ARF in our series (11.3 cases/year) is comparable to that reported by other African authors such as Ifeoma et al. in Nigeria (11.7 cases/year) [10], Bourquia et al. in Morocco (7 cases/year) [11] and Nebie in Burkina Faso (10.6 cases/year) [personal data]. It is however lower than Kiendrebeogo [personal data] and Balaka et al's series [12] which were respectively 19.6 and 30.6 cases per year. The incidence reported by Balaka et al. concerned only cases of post-hemolytic RF.

The incidence of CRF was one case per year in our series. It is lower than that of Kiendrebeogo [personal data] (4 cases per year), Nebie [personal data] (5 cases in six months). In Africa, Lagou et al [13] in Ivory Coast, Balaka et al. [12] in Togo found respectively four and five cases per year. For information, in Europe where there are efficient diagnostic means, data from dialysis records showed an incidence of 119 cases per year in Italy, 35.8 cases per year in Belgium [14].

The incidence variability of ARF and CRF is described by several authors [15]-[18]. Indeed, it varies from developed countries to developing countries [16] and also between the different ethnic groups [19]. It could be explained by the lack of consensual definition on ARF, the type of study and the method for recruiting patients. This difficulty related to the particular case of ARF could be lessened with the RIFLE (pRIFLE) criteria adapted to Pediatrics [20]. The use of these criteria remains, however, difficult in our conditions of practice.

The average age of CRF patients was $9.3 \pm 3.2$ years old. It is close to the average age of children in the series of Lagou et al. [13] (12.91 \pm 2.34 years old) but greater than that found in some European countries [14] like in 
Italy (6.9 years old), France (6.3 years old), Sweden (3.3 years old). This difference between European and African authors can be explained by the low activity of early screening of chronic kidney diseases and late consultations in our context, favored by the vague and non-specific symptomatology of CRF.

We found an important number of boys with RF compared to girls, just as in the study of Nebie [personal data] and in the literature [10] [12]. Kiendrebeogo [personal data] had found a parity between gender and females were predominantly found in Shaheen et al's study [21]. We have no explanation for this observation.

The main reasons for admission found in acute renal failure patients were diarrhea (100\%), anemia (29.4\%), fever (26.5\%). They correspond to the most frequent reasons for hospitalization in children. The ARF has no specific manifestations and often complicates the most frequent diseases of a child.

In patients with CRF, lower limbs edema or puffiness of the face were the most frequent reasons. Although not specific to CRF, their presence should prompt the search for a CRF and its complications by the clinicians of health structures at the lower levels of the health pyramid. We should therefore reinforce the continuing medical education and better equip these health structures.

The blood pressure measurement was done at the admission for only $27.7 \%$ of the patients. The main reason for the low measurement rate was the lack of pediatric blood pressure monitors in the department. This would contribute to a sub-screening of hypertension and, consequently, that of the CRF. Indeed, hypertension is the circumstance of diagnosis of CRF in some cases.

About two-thirds of our patients did not do an ultrasound. The latter has an important place in the exploration of kidney diseases. Its absence is a big impediment in the diagnostic process. The non-availability of this diagnostic test as well as some biological tests for the vast majority of our patients is mainly related to its financial inaccessibility for parents of affected patients.

Organic ARF was the most frequently presumed ARF mechanism in our study. The histological damage was probably an acute tubular necrosis in light of the context of occurrence of these ARFs. The presumed etiologies were dominated by infectious diseases such as severe malaria (50\%), viral hepatitis (14.7\%), acute post-streptococcal glomerulonephritis (8.8\%). Other African authors ([11] [22], personal data of Kiendrebeogo and Nebie) made the same observation. Dengue fever, viral disease, too often unrecognized, can simulate a severe malaria; it is increasingly cited as an infectious cause of ARF [23]. Better prevention and good management of infectious diseases, especially malaria, would reduce the incidence of ARF.

Regarding CRF, the suspected etiology was chronic glomerular nephropathy with nephrotic syndrome. Similar results have been reported in most of the African series ([11], personal data of Kiendrebeogo and Nebie), while the obstructive uropathies were the most found in the European series [14]. The high frequency of presumed chronic glomerular nephropathy is probably related to that of infectious diseases in our context. These are still common causes of glomerular nephropathy.

The mortality rate of $10.1 \%$ was very high, even though it was lower than that reported by Ladapo et al. [24]. This supports not only the severity of the cases but also the difficulties related to the lack of equipment, qualified staff, and the poverty of a large number of parents.

\section{Conclusion}

The incidence of RF was high at the PUHC-CDG of Ouagadougou. Its symptomatology was not specific. In light of the difficulties encountered in most public healthcare structures of the country in general, and at the PUHC-CDG in particular, the diagnosis of RF was founded only on the estimation of the GFR by using the formula of Pottel et al. This formula is independent of the height and weight that are simple parameters but not always available in our context. These same difficulties explain the high frequency of URF and the under-diagnosis of hypertension that is sometimes the circumstance of discovery of RF, especially chronic renal failure. The improvement of specialized human resources, and equipment of the PUHC-CDG (with simple tools like the blood pressure monitor, the measuring rod and urinary strips), as well as sufficient subvention of the health cost by the state would certainly contribute to a better screening, etiological research, and secondary prevention of RF in the Department of Medical Pediatrics of the PUHC-CDG.

\section{Conflict of Interest}

None. 


\section{References}

[1] Hoste, E.A. and Schurgers, M. (2008) Epidemiology of Acute Kidney Injury: How Big Is the Problem? Critical Care Medicine, 36, S146-S151. http://dx.doi.org/10.1097/CCM.0b013e318168c590

[2] Kellum, J.A., Bellomo, R. and Ronco, C.R. (2008) Definition and Classification of Acute Kidney Injury. Nephron Clinical Practice, 109, c182. http://dx.doi.org/10.1159/000142926

[3] Lengani, A., Kargougou, D., Fogazzi, G.B. and Laville, M. (2010) Acute Renal Failure in Burkina Faso. Néphrologie \& Thérapeutique, 6, 28-34. http://dx.doi.org/10.1016/j.nephro.2009.07.013

[4] Pottel, H., Hoste, L. and Martens, F. (2012) A Simple Height-Independent Equation for Estimating Glomerular Filtration Rate in Children. Pediatric Nephrology, 27, 973-979. http://dx.doi.org/10.1007/s00467-011-2081-9

[5] Hahn, J.M. (2005) Internal Medicine. 2nd Edition, Medical Checklists, Maloine, Paris, 797 p.

[6] Costa De Beauregard, M.A. and Rondeau, E. (2004) Acute Renal Failure-Anuria in Diseases and Major Syndromes. Revue du Praticien, 54, 81-88.

[7] Somu, S., Sundaram, B. and Kamalanathan, A.N. (2003) Early Detection of Hypertension in General Practice. Archives of Disease in Childhood, 88, 302. http://dx.doi.org/10.1136/adc.88.4.302

[8] Hogg, R.J., Furth, S., Lemley, K.V., Portman, R., Schwartz, G.J., Coresh, J., et al. (2003) National Kidney Foundation’s Kidney Disease Outcomes Quality Initiative Clinical Practice Guidelines for Chronic Kidney Disease in Children and Adolescents: Evaluation, Classification, and Stratification. Pediatrics, 111, 1416-1422. http://dx.doi.org/10.1542/peds.111.6.1416

[9] De Souza, V., Pottel, H., Hoste, L., Dolomanova, O., Cartier, R., Selistre, L., et al. (2015) Can the Height-Independent Pottele GFR Equation Be Used as a Screening Tool for Chronic Kidney Disease in Children? European Journal of Pediatrics, 174, 1225-1235. http://dx.doi.org/10.1007/s00431-015-2523-7

[10] Anochie, I.C. and Eke, F.U. (2005) Acute Renal Failure in Nigerian Children: Port Harcourt Experience. Pediatric Nephrology, 20, 1610-1614. http://dx.doi.org/10.1007/s00467-005-1984-8

[11] Bourquia, A., Chakib, F., Jennah, A. and Boughnama, A. (2002) Acute Renal Failure in Moroccan Children. Saudi Journal of Kidney Diseases and Transplantation, 13, 66-70.

[12] Balaka, B., Agbèrè, D., Bonkoungou, P., Gnamey, D., Kessie, K. and Assimadi, K. (2003) Post-Hemolytic Renal Failure in Children Deficient in Glucose-6-phosphate Dehydrogenase at Lome Hospital Center. Médecine tropicale, 63, 151-154.

[13] Lagou, D.A., Gnionsahe, D.A. and Tia, W.M. (2006) Chronic Renal Failure in Children in Hospital Environment, in Ivory Coast: Study of 24 Cases. Revue Internationale des Sciences Médicales, 8, 18-22.

[14] Harambat, J., Van Stralen, K.J., Kim, J.J. and Tizard J.E. (2012) Epidemiology of Chronic Kidney Disease in Children. Pediatric Nephrology, 27, 363-373. http://dx.doi.org/10.1007/s00467-011-1939-1

[15] Bradley, W.A. and Chadha, V. (2007) Chronic Kidney Disease in Children: The Global Perspective. Pediatric Nephrology, 22, 1999-2009. http://dx.doi.org/10.1007/s00467-006-0410-1

[16] Cerdà, J., Bagga, A., Kher, V. and Chakravarthi, R.M. (2008) The Contrasting Characteristics of Acute Kidney Injury in Developed and Developing Countries. Nature Reviews Nephrology, 4, 138-153. http://dx.doi.org/10.1038/ncpneph0722

[17] Cochat, P., Mourani, C., Exantus, J., Bourquia, A., Martinez-Pico, M., Adonis-Koffy, L., et al. (2009) Pediatric Nephrology in Developing Countries. Médecine tropicale, 69, 543-547.

[18] Esezobor, C.I., Ladapo, T.A., Osinaike, B. and Lesi, F.E. (2012) Paediatric Acute Kidney Injury in a Tertiary Hospital in Nigeria: Prevalence, Causes and Mortality Rate. PLoS ONE, 7, e51229. http://dx.doi.org/10.1371/journal.pone.0051229

[19] Muntner, P., Newsome, B., Kramer, H., Peralta, C.A., Kim, Y., Jacobs Jr., D.R., et al. (2012) Racial Differences in the Incidence of Chronic Kidney Disease. Clinical Journal of the American Society of Nephrology, 7, 101-107. http://dx.doi.org/10.2215/CJN.06450611

[20] Stuart, L.G. and Devarajan, P. (2011) Acute Kidney Injury in Childwood: Should We Be Worried about Progression to CKD? Pediatric Nephrology, 26, 509-522. http://dx.doi.org/10.1007/s00467-010-1653-4

[21] Shaheen, I.S., Watson, R.A. and Harvey, B. (2006) Acute Renal Failure in Children: Etiology, Treatment and Outcome. Saudi Journal of Kidney Diseases and Transplantation, 17, 153-158.

[22] Assounga, A.G., Assambo-Kieli, C., Mafoua, A., Moyen, G. and Nzingoula, S. (2000) Etiology and Outcome of Acute Renal Failure in Children in Congo-Brazzaville. Saudi Journal of Kidney Diseases and Transplantation, 11, 40-43.

[23] Oliveira, J.F.P. and Burdmann, E.A. (2015) Dengue-Associated Acute Kidney Injury. Clinical Kidney Journal 8, 
681-685. http://dx.doi.org/10.1093/ckj/sfv106

[24] Ladapo, T.A., Esezobor, C.I. and Lesi, F.E. (2014) Pediatric Kidney Diseases in an African Country: Prevalence, Spectrum and Outcome. Saudi Journal of Kidney Diseases and Transplantation, 25, 1110-1116. http://dx.doi.org/10.4103/1319-2442.139976 